\title{
Exotic plants contribute positively to biodiversity functions but reduce native seed production and arthropod richness
}

\author{
Susan C. Cook-Patton ${ }^{1}$ and Anurag A. Agrawal \\ Department of Ecology and Evolutionary Biology, Cornell University, Ithaca, New York 14853 USA
}

\begin{abstract}
Although exotic plants comprise a substantial portion of floristic biodiversity, their contributions to community and ecosystem processes are not well understood. We manipulated plant species richness in old-field communities to compare the impacts of native vs. exotic species on plant biomass, seed production, and arthropod community structure. Plants within diverse communities, regardless of whether they were native or exotic, had higher biomass and seed production than in monocultures and displayed positive complementarity. Increasing native or exotic plant richness also enhanced the richness of arthropods on plants, but exotics attracted fewer arthropod species for a given arthropod abundance than did natives. Additionally, when exotic and native plants grew together, exotics suppressed seed production of native species. Thus, exotic plants appear to contribute positively to some biodiversity functions, but may impact native communities over longer time frames by reducing native seed production and recruiting fewer arthropod species.
\end{abstract}

Key words: arthropod richness; biodiversity; biomass; Dryden, New York, USA; exotic plants; invasion; mono- vs. polyculture; native plants; old-field habitat; plant-insect interactions; seed production.

\section{INTRODUCTION}

The composition and diversity of most plant communities are rapidly changing due to the extirpation of natives and the introduction of exotics (Sala et al. 2000). Although exotics may reduce richness by displacing native species (Mack et al. 2000), they may also increase local species richness if they integrate into existing native communities (Sax et al. 2002, Marks et al. 2008, Tilman 2011). For example, in the Cayuga region of New York where we conducted our research, plant species richness has increased more than $50 \%$ over the past century due to the introduction of exotics (Marks et al. 2008). However, the specific effect of exotics on biodiversityecosystem function relationships has received little attention. Although some biodiversity manipulations have incorporated exotics into their species pools (e.g., Dukes 2001, Reich et al. 2001, Fridley 2002), only a handful of experiments explicitly have explored the contribution of exotics to biodiversity-ecosystem function relationships (Wilsey et al. 2009, Isbell and Wilsey 2011, Wilsey et al. 2011). Thus, we currently have a limited ability to understand the consequences of changes in species richness resulting from the widespread exchange of species across the globe.

Decades of work have established a strong link between plant biodiversity and ecosystem functioning,

Manuscript received 27 April 2013; revised 24 October 2013; accepted 26 November 2013. Corresponding Editor: B. J. Cardinale.

${ }^{1}$ Present address: Smithsonian Environmental Research Center, 647 Contees Wharf Rd., Edgewater, Maryland 21037 USA. E-mail: cook-pattons@si.edu especially a positive relationship between plant species richness and productivity (reviewed in Hooper et al. 2005, Cardinale et al. 2011). One might expect biodiversity-productivity relationships to differ between native-dominated and exotic-dominated assemblages for several reasons. First, native plants have interacted with their environment for millennia, whereas most exotic species in North America arrived after European settlement (Mack and Lonsdale 2001). Interactions over evolutionary time may have resulted in greater niche partitioning among the natives, which would lead to more efficient resource use and higher biomass production in native compared to exotic communities. One of the few manipulations of native and exotic richness (Wilsey et al. 2009) found results consistent with this prediction: exotics tended to dominate in diverse mixtures, leading to loss of diversity whereas diversity was maintained in native-only communities. We also predicted that biodiversity-biomass production relationships might differ among native and exotic assemblages because herbivores have been shown to reduce native biomass more heavily than exotic biomass (Keane and Crawley 2002, Agrawal et al. 2005), especially when they are in monocultures (Root 1973). If exotics are rarely attacked, then we would predict their performance to be consistently high in either species monocultures or mixtures (and thus less likely to show gains in biomass with increasing plant richness; e.g., Schnitzer et al. 2011).

Long-standing theoretical and experimental work has also established a link between plant diversity and arthropod community structure (e.g., Tahvanainen and Root 1972, Andow 1991, Haddad et al. 2001, Cook- 
Patton et al. 2011). Increasing plant species richness may result in a more diverse fauna because arthropods specialize on distinct host plant species; thus, diverse plant communities attract more types of arthropod species (resource specialization hypothesis; Hutchinson 1959, Murdoch et al. 1972, Strong et al. 1984). In addition, niche theory predicts that resource specialization among arthropods will reduce competition and thus increase arthropod abundance (Chesson 2000). Even in the absence of resource specialization, diverse communities may attract more arthropod species because diverse plant communities are generally more productive (Cardinale et al. 2007). More abundant plant resources can support more arthropod individuals and thus increase the probability of observing rare species (more individuals hypothesis; Srivastava and Lawton 1998). Although these hypotheses are not mutually exclusive, statistical methods can be used to disentangle the extent to which changes in dependent arthropod communities are impacted by plant biomass and arthropod abundances (Gotelli and Colwell 2001). To our knowledge, there have been no experimental comparisons of how changes in native and exotic plant richness impact arthropod communities. We predicted that resource specialization dynamics would occur more frequently in native communities, because exotic plant species typically have a depauperate fauna of specialists in their introduced range (Keane and Crawley 2002, Agrawal et al. 2005).

Here we present a two-year field experiment to investigate how changes in native and exotic plant species richness impacted plant biomass, seed production, and arthropod community structure. Using monocultures, single-origin polycultures (containing either eight native or eight exotic species), and mixed-origin polycultures (containing four native and four exotic species), we tested the hypotheses that (1) plant diversity-biomass production relationships would differ in native vs. exotic-dominated plots, (2) that native plant performance would be impacted by the presence of exotic species in mixed-origin polycultures (and vice versa), and (3) that changes in native and exotic plant richness would alter arthropod community structure. This study advances previous work (Wilsey et al. 2009, Isbell and Wilsey 2011, Wilsey et al. 2011), first by measuring a component of sexual reproduction (seed production) to assess how these systems may respond to changes in richness, second by including a mixed-origin polyculture to address how native performance is altered by the presence of exotics (and vice versa), and finally by analyzing arthropod community structure to determine how changes in plant biodiversity cascaded to higher trophic levels.

\section{Methods}

Study species and experimental design

We selected 16 native and 16 exotic species that commonly co-occur in New York old fields (see details in Appendix A: Table A1). We used primarily forbs, because vegetational transects in adjacent old fields showed that $80 \%$ of species were forbs (A. Agrawal, unpublished data). We also excluded legumes because the transect data showed native legumes to be very uncommon and we wanted to avoid including an influential functional group (i.e., Hooper et al. 2005) in the exotic species pool only. Seeds derived from multiple populations around Ithaca, New York (USA), except for Elymus trachycaulus and E. repens seeds, which came from southern Ontario (Canada). Our native and exotic species pools did not differ substantially in their mean phenotypes for 10 functional traits (Appendix B). Only one trait differed between natives and exotics, and one significant trait of 10 may have been due to chance (binomial expansion test, $P=0.315$ ). Methods for trait measurements and analyses can be found in Appendix B.

In April 2008, we cold-stratified seeds $\left(4^{\circ} \mathrm{C}, 4\right.$ days), sowed them into 96-well trays filled with commercial potting soil (Pro-mix "BX" with biofungicide, Premier Tech Horticulture, Quakertown, Pennsylvania, USA), and thinned seedlings to a single individual per well. The seedlings spent five weeks in the greenhouse (14:10 hour light: dark cycle, 5 weeks), with ad libitum water and weekly fertilizer (21-5-20 NPK, $150 \mathrm{ppm}$ ), and then a week in an outdoor mesh cage to field harden.

In June 2008, we established $0.5 \mathrm{~m}$ diameter plots in a plowed field near Dryden, New York (USA) (42 $27^{\prime} 46^{\prime \prime}$ $\left.\mathrm{N}, 76^{\circ} 26^{\prime} 37^{\prime \prime} \mathrm{W}\right)$. All plots contained eight individuals arrayed in a ring and were $1 \mathrm{~m}$ from other plots. We initially planted two monocultures per species. However, due to mortality, two species (Lobelia inflata and Silene vulgaris) appeared once in monoculture and one species (Asclepias syriaca) not at all $(N=60$ monocultures remaining). In addition, our Dipsacus sativus seeds were contaminated with a few $D$. laciniatus seeds and a few $D$. laciniatus occurred in the D. sativus monocultures (see Appendix A and Appendix $\mathrm{C}$ for details on how we dealt with this issue). Polycultures contained eight different species and were either "single-origin polycultures" (all native species, $N=28$, or all exotic species, $N=30$ ) or "mixed-origin polycultures" (half native/half exotic, $N=$ 31). We randomly assembled polyculture compositions, but ensured that species occurred with fairly equal frequency across the experiment.

After planting, we took several steps to maintain the experiment. We allowed the area surrounding each plot to be colonized naturally from the seed bank and trimmed this buffer vegetation once at the beginning of the 2009 field season to facilitate movement among plots. Throughout 2008 and 2009, we hand-weeded all emergent vegetation within the plots to maintain the original diversity treatment. We also removed any new individuals from seeds produced in 2008 to maintain the plant density across years. Finally, in June 2009 we replaced all Verbascum thapsus plants with a new species, Leucanthemum vulgare, because $V$. thapsus did 
not survive in the conditions of our experiment. We also replanted annuals and biennials that had completed their life cycle in 2008, as well as individuals that had died of unknown causes (Appendix A: Table A1).

\section{Plant performance}

For the species that flowered $(N=13$ exotic and 15 native species), we counted fruit number on each plant using a standardized protocol for each species. For example, for species with a few conspicuous fruits, we counted every individual fruit; for species with large inflorescences, small flowers, and many seed heads (e.g., most Asteraceae), we counted every branch of the inflorescence. We then collected a subset of fruits (mean $\sim 26$ fruits/species) to count seeds per fruit. Seeds per fruit did not differ among treatments, so we pooled data across treatments to determine a single mean for each species. We then estimated individual seed production as fruit number $\times$ mean seeds per fruit for each species. For all species, we also harvested aboveground biomass of each individual plant between mid-September and midOctober 2009, dried it fully, and weighed it to the nearest $0.1 \mathrm{~g}$.

\section{Insect surveys}

We surveyed arthropod communities three times during 2009 (early June, mid-July, and late July). We first estimated leaf damage using a $0-100 \%$ scale with $5 \%$ intervals, where $0 \%$ corresponded to no damage and $100 \%$ to consumption of all leaves and stems. We then carefully scanned every plant visually to record the number and abundance of all arthropods visiting each plant, including herbivores, predators, and pollinators. Arthropods were identified to species if possible, but were primarily grouped into morphospecies $(N=236$ across the experiment). Because we used morphospecies, our values of arthropod richness are probably conservative estimates of true species richness, given that species with similar morphology (i.e., small, black bees) were lumped into a single group. Additionally, our use of morphospecies does not allow us to distinguish between arthropods of native vs. exotic origin. However, exotic specialists did occur in our samples (i.e., Calophasia lunula caterpillars on Linaria vulgaris, Hypera rumicis weevils on Rumex crispus, and Chrysolina quadrigemina leaf beetles on both the native and exotic Hypericum species).

\section{Statistical analyses}

Hypothesis I: Diversity-biomass production relationships will vary in native vs. exotic-dominated plots.-All analyses were conducted in $\mathrm{R}$ version 2.15 .2 ( $\mathrm{R}$ Development Core Team 2012). To investigate variation in biomass among treatments, we calculated total aboveground biomass in each plot, $(\ln +1)$-transformed the data, and analyzed them with a two-way ANOVA with origin (native or exotic) and richness (monoculture or single-origin polyculture) as main effects. Note that we excluded mixed-origin polycultures here to enable analysis and interpretation of the origin $\times$ richness interaction. For completeness, we note mean biomass production for this treatment in the results and separately analyze the biodiversity effect on all three polyculture types. We also used the same two-way ANOVA model to analyze ln-transformed herbivore damage data.

Higher performance in diverse assemblages may occur via multiple routes (Loreau and Hector 2001). Positive complementarity occurs when species have higher average biomass in polyculture than is expected from monoculture plots. Positive selection occurs when highly productive monoculture species disproportionately occupy polycultures, whereas negative selection occurs when species with low productivity in monocultures show the most gains in polyculture. We assessed the extent of complementarity and selection for both singleorigin polycultures as well as the mixed-origin polycultures. Detailed methods for these calculations, as well as our modifications to account for mortality and seed contamination, can be found in the Appendix C.

Hypothesis II: Native plant performance will be impacted by the presence of exotics in mixed-origin polycultures (and vice versa).-To quantify differences in seed production among polyculture types, we first standardized each estimate of seed production by the mean seed production across all treatments for that species, so that variation in absolute seed number among species did not drive the results. Then, we calculated mean relative seed production per species in both the single-origin and mixed-origin polycultures $(N$ $=56 ; 15$ species $\times 2$ polyculture types for the natives and 13 species $\times 2$ polyculture types for the exotics; four species did not flower; Appendix A: Table A1). We analyzed this species-focused data set with a two-way ANOVA, with origin (native or exotic) and polyculture type (single origin or mixed origin) as predictors of seed set.

Hypothesis III: Changes in native and exotic plant richness will alter arthropod community structure.-We calculated arthropod abundance as the mean number of individuals within a plot, and arthropod richness as the mean number of species within a plot across the three sampling dates. We used these data in factorial two-way ANOVAs with richness (monocultures vs. single-origin polycultures) and origin (native vs. exotic) as predictors. Abundance was $(\ln +1)$-transformed to improve normality. Note that as with the biomass analyses, the mixed-origin polyculture data were excluded from the initial analyses to enable assessment of the richness $\times$ origin interaction, but we show the means for this treatment in Fig. 4a, c.

To account for the effect of plant biomass on abundance, we divided arthropod abundance by plot biomass, $(\ln +1)$-transformed the data, and then employed the same two-way ANOVA. Finally, to account for the effect of arthropod abundance on our 

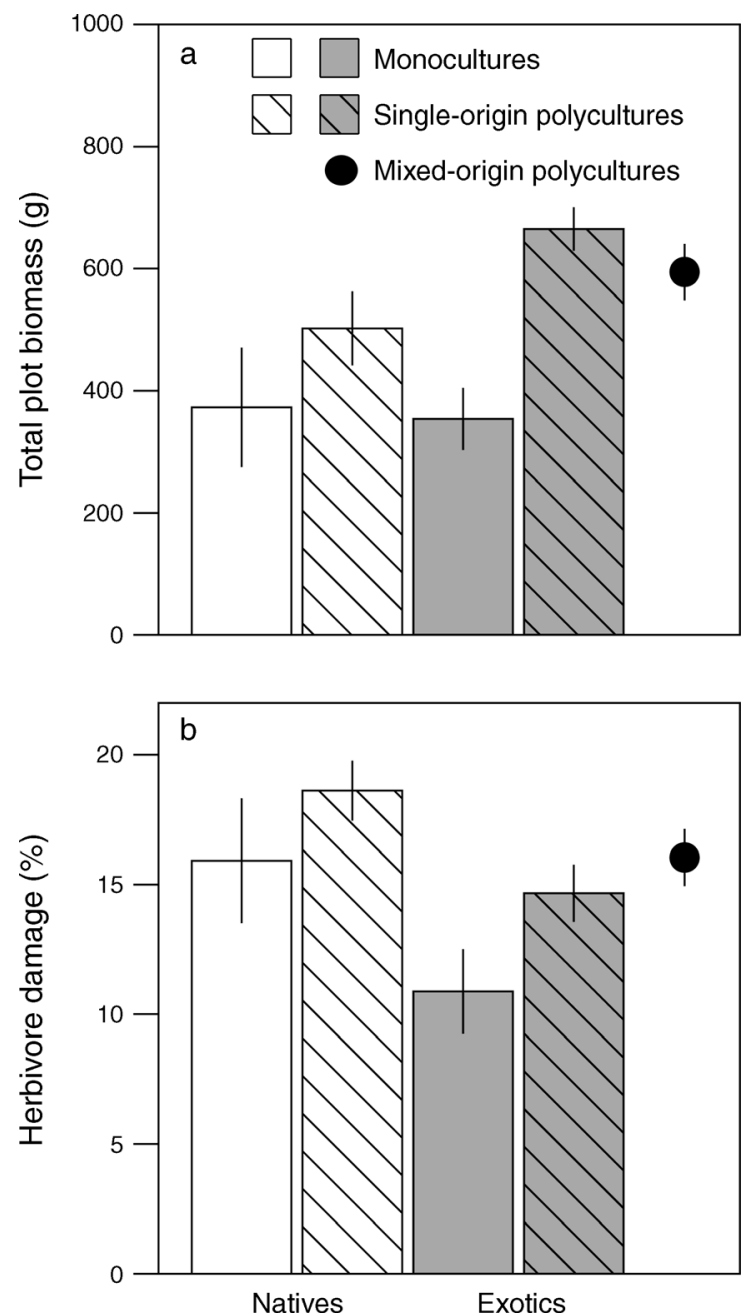

FIG. 1. (a) Total aboveground biomass and (b) herbivore damage in the monocultures (unhatched bars) and single-origin polycultures (hatched bars) composed of native (white bars) and exotic (gray bars) plant species in a New York old-field community (values are means $\pm \mathrm{SE}$ ). Biomass and herbivore damage (means $\pm \mathrm{SE}$ ) in mixed-origin polycultures (solid circles) are also shown in each panel for comparison. Singleorigin polycultures contained either eight native or eight exotic species, and mixed-origin polycultures contained four native and four exotic species. We estimated leaf damage using a 0 $100 \%$ scale with $5 \%$ intervals, where $0 \%$ corresponded to no damage and $100 \%$ to consumption of all leaves and stems.

estimates of species richness, we used individual-based rarefaction to standardize the richness data to 10 individuals per plot (Gotelli and Colwell 2001) and analyzed the rarefied data with the same model (rarefy in the $\mathrm{R}$ vegan 1.17-3 package; Oksanen et al. 2011).

\section{Results}

Hypothesis I: Diversity-biomass production relationships will vary in native vs. exotic-dominated plots.-We found that, across species, increasing plant richness enhanced biomass production (Fig. 1a; richness, $F_{1,115}=$ $32.9, P<0.0001$ ), with single-origin polyculture plots producing $61 \%$ more biomass than monocultures. There was neither an effect of plant origin on biomass $\left(F_{1,115}=\right.$ $0.1, P=0.699)$ nor an interaction between richness and origin $\left(F_{1,115}=2.1, P=0.146\right)$. Although we expected natives to respond more strongly than exotics to the diversity manipulation, we found the reverse trend. Exotic polycultures produced $88 \%$ more biomass than exotic monocultures compared to native polycultures, which produced $35 \%$ more than native monocultures. Mixed-origin polycultures were intermediate to the native-only and exotic-only polycultures, producing $64 \%$ more biomass than monocultures.

All polyculture types showed positive complementarity, indicating that species had higher performance in mixture than in monoculture, on average (Fig. 2). Similar to the preceding analysis, the trend was toward greater complementarity among exotic compared to native polycultures, although it was not statistically distinguishable among the three treatments. We found no evidence for a selection effect (Fig. 2) or transgressive overyielding. Indeed, the exotic Centaurea stoebe monocultures produced greater than threefold more biomass (2024 g, on average) than the mean biomass of the native-only, exotic-only, and mixed-origin polycultures (502 g, $664 \mathrm{~g}$, and $594 \mathrm{~g}$, respectively), as well as nearly double the biomass of the most productive native monoculture (Solidago juncea, $1029 \mathrm{~g}$ ).

The overall gains in biomass in polyculture were not explained by differential herbivory. In fact, damage increased $24 \%$ across all polycultures compared to

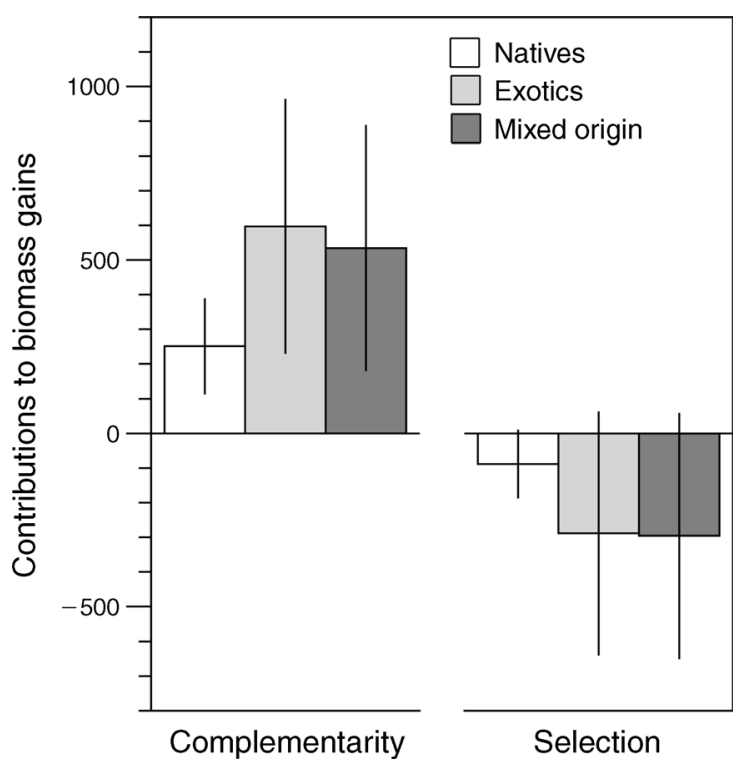

FIG. 2. Magnitude of complementarity and selection effects in native (white bars), exotic (light gray bars), and mixed-origin (dark gray bars) polycultures (values are means with $95 \%$ CI). Positive complementarity occurs when species, on average, produce more biomass in polyculture than expected from monoculture. Negative selection occurs when smaller monoculture species benefit more from the diversity manipulation than do larger monoculture species. 


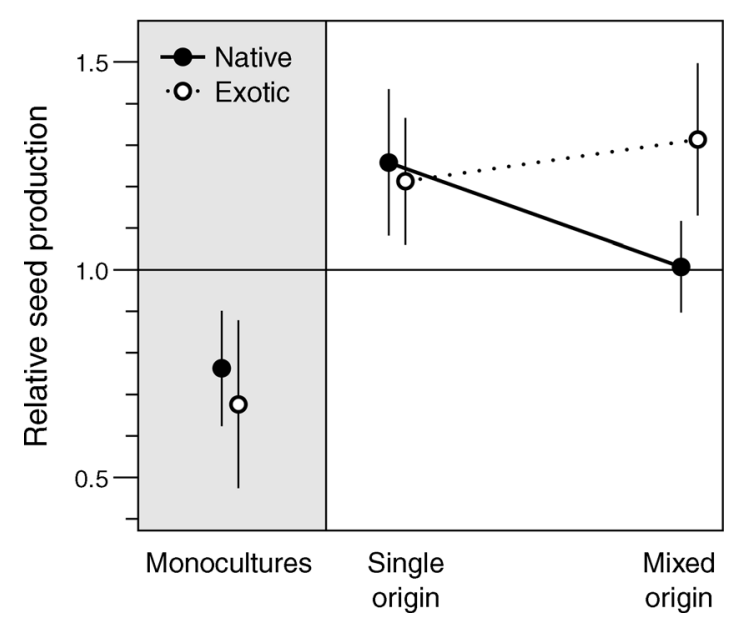

FIG. 3. Relative seed production (proportional change from the mean production across all treatments, which was set to 1.0) in mixed-origin and single-origin polycultures (means with $95 \% \mathrm{CI}$ ). Native seed production (mean of 15 species) declined in mixed-origin polycultures, while exotic seed production (mean of 13 species) increased. Points that fall on the 1.0 line are equal to mean relative seed production across treatments. We include the means (with 95\% CI) of seed production in native and exotic monocultures for comparison.

monocultures $\left(F_{1,115}=15.9, P<0.001\right.$; Fig. $\left.1 \mathrm{~b}\right)$, and there was no interaction between plant origin and richness $\left(F_{1,115}=0.2, P=0.626\right)$. As expected, exotic monocultures and polycultures had the lowest levels of herbivore damage $(\sim 11 \%$ and $\sim 15 \%$ of leaf tissue removed, respectively). Native polycultures had the highest levels of damage ( $\sim 19 \%$ of leaf tissue removed) and natives had $35 \%$ higher damage than exotics overall $\left(F_{1,115}=8.1, P=0.005\right)$. Damage on mixed-origin polycultures was intermediate to native-only and exoticonly polycultures, with $\sim 16 \%$ of leaf tissue removed.

Hypothesis II: Native plant performance will be impacted by the presence of exotics in mixed-origin polycultures (and vice versa).-To examine the consequences of exotic biodiversity on native communities, we examined how seed production varied among our polyculture treatments. In a species-level analysis, we found that exotics growing among natives had 14\% higher seed production than when they grew among other exotics. In contrast, natives produced $20 \%$ fewer seeds when growing among exotics than when growing with other natives (Fig. 3; origin $\times$ polyculture-type, $\left.F_{1,54}=5.6, P=0.020\right)$. There was no main effect of polyculture-type $\left(F_{1,54}=0.3, P=0.559\right)$ or origin $\left(F_{1,54}=\right.$ $0.8, P=0.349$ ). It appears that differential plant size drove this result, because when we divided relative seed production by biomass, the interaction between plant origin and polyculture type was no longer significant $\left(F_{1,54}=0.2, P=0.635\right)$. Thus, our species-level analyses suggest that exotics are suppressing native biomass enough to alter seed production.
Hypothesis III: Changes in native and exotic plant richness will alter arthropod community structure.-We found that arthropod abundance was $61 \%$ higher in polycultures than in monocultures $\left(F_{1,115}=31.4, P<\right.$ 0.0001; Fig. 4a). However, natives did not accumulate more arthropods than exotics $\left(F_{1,115}=0.4, P=0.506\right)$, and there was no interaction between plant origin and abundance $\left(F_{1,115}=0.5, P=0.467\right)$. Similarly, arthropod richness was $91 \%$ higher in polyculture $\left(F_{1,115}=\right.$ 66.6, $P<0.0001$; Fig. 4c), but there was no impact of origin $\left(F_{1,115}=3.0, P=0.084\right.$; origin $\times$ richness $F_{1,115}=$ $1.2, P=0.263)$. When we examined just the polyculture data, we also observed no difference in abundance $\left(F_{2,86}\right.$ $=0.3, P=0.728)$ or richness $\left(F_{2,86}=0.9, P=0.399\right)$ of accumulated arthropods.

To determine whether patterns of arthropod abundance were driven by differences in biomass among treatments, we divided arthropod abundance by plant biomass and found no treatment effects (for richness, $F_{1,110}=0.9, P=0.333$; for origin, $F_{1,110}=0.1, P=0.709$; for richness $\times$ origin, $F_{1,110}=1.3, P=0.260$; Fig. $4 \mathrm{~b}$ ); thus, differential plant biomass drove arthropod abundance effects rather than plant richness. To examine whether patterns of arthropod richness were driven by arthropod abundance, we used rarefaction to standardize the data to a common abundance across plots. Rarefied species richness was still higher in polycultures by $45 \%$ compared to monocultures (for plant richness, $F_{1,115}=23.1, P<0.0001$; Fig. 4 d) indicating that diverse plant communities recruit a greater diversity of arthropods after accounting for differences in arthropod abundance. Although this pattern was true for both native and exotic communities (for plant richness $\times$ origin, $F_{1,115}=0.6, P=0.410$ ), we found that rarefied richness was $24 \%$ higher in native compared to exotic plots (for origin, $F_{1,115}=8.9, P=0.003$ ). Thus, by controlling for differences in arthropod abundance, we found that native plants recruited more arthropod species than did exotic plants.

\section{DisCUSSION}

Exotic species are becoming an increasingly common component of our natural landscapes (Sax et al. 2002, Marks et al. 2008). Our results suggest that these increases in species richness have mixed consequences for ecosystems. Exotic polycultures produced equally if not more biomass than native polycultures and recruited an abundant and diverse arthropod fauna. However, when we controlled for differences in arthropod abundance among treatments, we found that exotic polycultures recruited fewer arthropod species than did native polycultures. In addition, when natives were grown with exotics, they had substantially reduced seed production.

Counter to our prediction that native plant communities would respond more strongly to the manipulation of plant species richness than exotic communities, we found that biomass increased almost twofold more in 

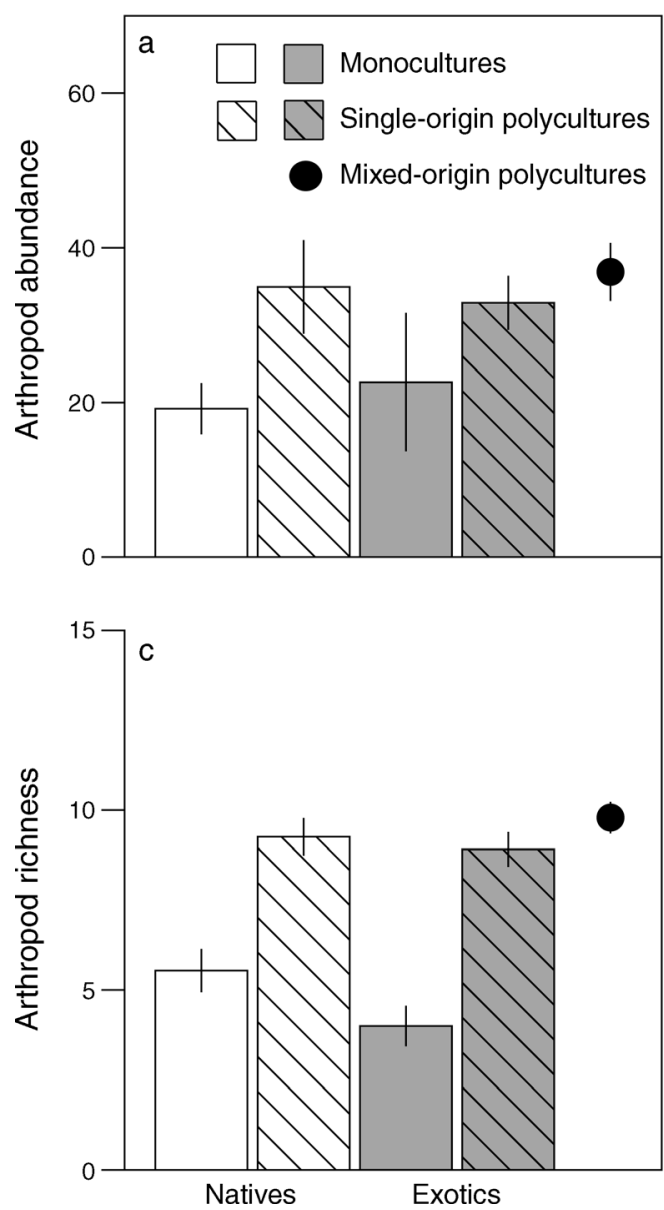
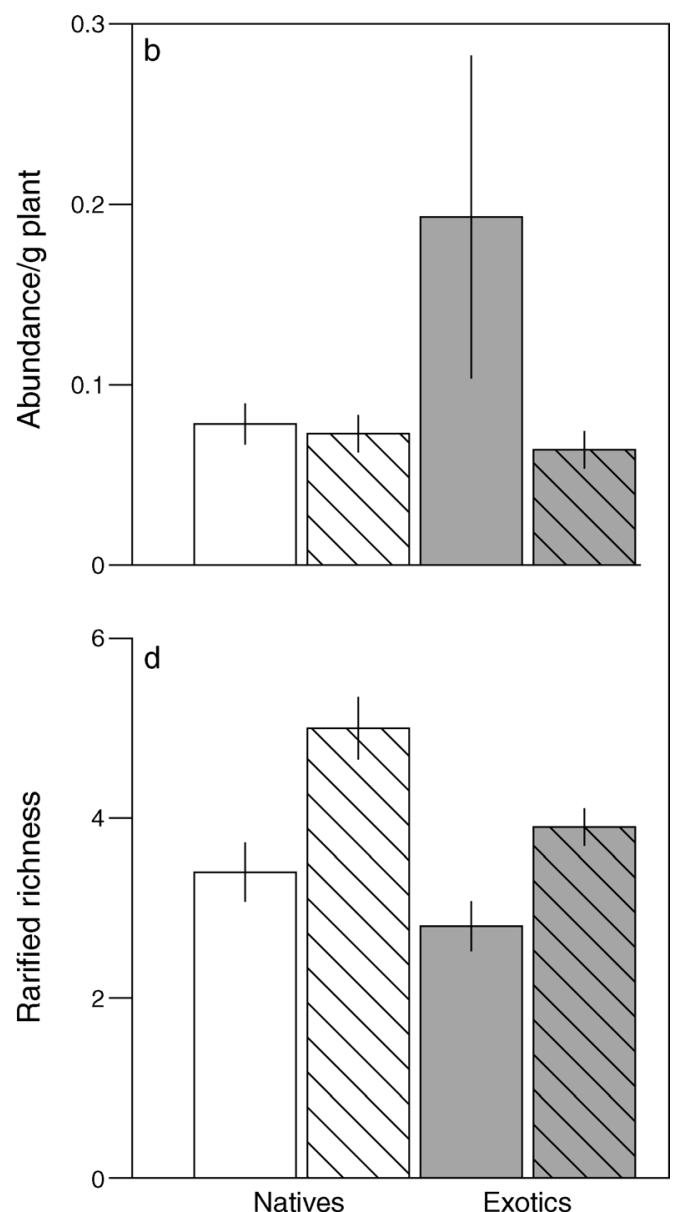

FIG. 4. Arthropod response to changes in plant richness and origin (values are means \pm SE): (a) arthropod abundance; (b) arthropod abundance divided by plant biomass; (c) arthropod richness; and (d) rarified arthropod richness in monocultures (unhatched bars) and single-origin polycultures (hatched bars) composed of native (white bars) and exotic (gray bars) plant species. Mixed-origin polycultures (solid circles, means \pm SE) are also shown for comparison. Rarified richness standardized the richness data to 10 arthropod individuals to control for variation in arthropod abundance among plots.

exotic polycultures than in native polycultures. This result contrasts with one of the few previous studies comparing the contribution of native vs. exotic species to ecosystem function (Isbell and Wilsey 2011). They manipulated grassland diversity and found that mixtures of four native grass species produced $42 \%$ more biomass than monocultures, whereas monocultures and polycultures of exotic grasses did not differ. However, consistent with our results, Wilsey et al. (2009) found that biomass increased more in exotic-only polycultures than in native-only polycultures, relative to monocultures. Wilsey et al. (2009) observed complementarity in native polycultures, but selection effects in exotic polycultures. Later work suggested that exotics competed with each other more intensely than did natives, because they had more rapid and synchronous growth (Wilsey et al. 2011). In contrast, we attribute biomass gains in both native-only and exotic-only polycultures to positive complementarity. When we further examined our trait data and calculated the variance in bolting time and flowering time among species within each polyculture plot, we did not find strong evidence for differences in synchronicity (e.g., phenological variance) among native and exotic polycultures (Appendix D).

Our choice of experimental study system may explain why, counter to predictions, exotic communities responded more positively to the richness manipulation than did the natives, which presumably had greater evolutionary time to partition niche space. Fields were uncommon in the northeastern USA, where this experiment was conducted, before humans cleared the land (Cronon 1983). Historically, the species that now flourish in old-field communities probably grew in marginal habitats where forest cover did not establish or in forest openings following tree-downs or fire (Marks 1983). If the disturbed and highly productive old-field habitat in which these species now grow and interact does not resemble the communities in which these species evolved, then perhaps we cannot expect stronger niche partitioning among the natives than 
among the exotics. Additional comparisons of native and exotic richness in different habitats, with species that have varying histories of interaction, and more precise measures of niche partitioning (e.g., Carroll et al. 2011) would help to resolve this issue.

Exotics had higher seed production when they grew among other exotic species, but they substantially suppressed the seed production of natives. There are several mechanisms by which exotics might reduce natives' seed production, including competition (Levine et al. 2003), disruption of pollination services (Traveset and Richardson 2006), or increased susceptibility to herbivory (Lau and Strauss 2005). Although we do not know whether exotics alter pollinator efficacy, we found no evidence for herbivory-mediated interactions between natives and exotics. Competition between natives and exotics, in contrast, may be partly responsible, because when we accounted for changes in biomass (by dividing relative seed production by plant biomass to obtain number of seeds per gram), the previously significant interaction between plant origin and polyculture type (Fig. 3) was no longer significant. We interpret this to mean that exotics are suppressing native biomass enough to reduce reproduction.

Our results on seed production highlight an important question in biodiversity-ecosystem function research. Specifically, can we expect the enhanced performance of diverse communities, which has been repeatedly observed in short-term diversity manipulations, to persist through time? A meta-analysis of diversity effects on biomass production found that diversity effects grew larger through time (Cardinale et al. 2007). However, the long-term provisioning of ecosystem services clearly depends on the stability of the community providing those services (Turnbull et al. 2013). Our experiment only ran for two years, but if the suppressive effect of exotics on native seed production persists through time (and if recruitment of natives is seed limited), then exotics potentially could disrupt biodiversity-ecosystem function relationships by reducing native diversity. Consistent with this idea, one multi-decadal examination of successional dynamics found that native species richness in invaded communities declined because the exotic species reduced the colonization rates of natives (Yurkonis et al. 2005). However, we can only speculate about how exotic diversity will impact long-term ecosystem functioning, because multiyear diversity experiments that manipulate native and exotic diversity do not exist. Indeed, the majority of diversity manipulations exclusively use native species, despite the prevalence of exotics in our landscape (Sala et al. 2000). In addition, even though local floral richness may increase due to the addition of exotic species (Sax et al. 2002, Marks et al. 2008, Tilman 2011), community compositional changes (i.e., changes in evenness) are likely to occur following species introductions, and studying the impacts of alterations in evenness due to the introduction of exotics would be a promising area of future study. Interestingly, if we had examined only plant biomass, we would have drawn different conclusions about the effect of exotics on ecosystem function. This highlights the importance of incorporating measures of seed production into biodiversity experiments (Johnson et al. 2006, Carroll et al. 2011).

To our knowledge, we present the first comparison of how changes in native and exotic richness impact arthropod community structure. We found that increasing native or exotic diversity resulted in equivalent increases in the abundance and richness of the faunal community. This partially corresponds to other experimental work, which showed that polycultures have more diverse herbivore communities than monocultures (e.g., Siemann et al. 1998, Haddad et al. 2001, CookPatton et al. 2011). However, while herbivore richness may be higher in mixtures than in monocultures, theory predicts that herbivore abundance and damage should be lower (i.e., the resource concentration hypothesis and the enemies hypothesis; Root 1973). We found, in contrast, that herbivore abundance and damage were higher in polyculture. Although we did not partition arthropods by diet breadth, future work that distinguishes between generalist and specialist herbivores may help to resolve this, because these herbivore types are expected to respond differently to changes in plant diversity (Root 1973, Karban et al. 2010). Specialists are expected to be less frequent in diverse assemblages (Root 1973), but generalists may be more abundant due to the beneficial effects of diet-mixing (Karban et al. 2010) and the greater abundance of plant biomass present.

We also predicted that resource specialization (Strong et al. 1984) was more likely to operate in native communities, whereas abundance-driven accumulation (Srivastava and Lawton 1998) would apply in both native and exotic communities. Our results partially support these predictions. Overall, we found that increasing native or exotic plant species richness resulted in a more abundant and diverse arthropod community. Although arthropod abundance appears to be determined mostly by plant biomass, the mechanisms underlying richness were more complicated. The increase in arthropod richness in polycultures was not simply due to the presence of more arthropod individuals in polyculture, because rarefied richness was significantly higher in both native and exotic polycultures compared to their respective monocultures. This suggests that resource specialization may be operating and that diverse plant communities recruited more arthropod species because they offered a greater diversity of resources (Hutchinson 1959, Murdoch et al. 1972, Strong et al. 1984). However, natives recruited more arthropod species per arthropod individual than did exotics and natives received $35 \%$ more herbivory than did exotics. Other studies, which have compared arthropod communities on individual native and exotic species, have often found reduced faunal richness on 
exotics (e.g., Agrawal et al. 2005, Burghardt et al. 2010). These results combine to suggest that even though increasing the richness of exotic species may enhance arthropod richness and abundance, equivalently diverse native plant communities may better support a diverse fauna.

Given the growing preponderance of exotic species in our landscapes and the fact that regional-scale richness often increases due to their introduction (Sala et al. 2000, Sax et al. 2002, Marks et al. 2008, Mascaro et al. 2012), it is remarkable that so few biodiversity experiments have independently manipulated native and exotic species. Our work, as well as that of others, suggests that exotic species can have positive effects on ecosystems (Jahner et al. 2011, Mascaro et al. 2012). Nonetheless, our analyses of seed production and arthropod community structure suggest that long-term negative effects of exotics may counterbalance any short-term positive effects.

\section{ACKNOWLEDGMENTS}

We thank A. C. Erwin, A. P. Hastings, L. Schunk, and S. H. McArt for field assistance, P. Kotanen for Elymus seeds, J. Simonis for statistical advice, and B. Blossey, L. J. Martin, S. H. McArt, J. Sparks, and A. Agrawal's lab for invaluable discussion. We thank reviewers for their comments on earlier versions of the manuscript. This work was supported by a grant from Cornell's IGERT in Biogeochemistry and Environmental Biocomplexity to S. C. Cook-Patton and NSF-DEB 1118783 to A. A. Agrawal.

\section{Literature Cited}

Agrawal, A. A., P. M. Kotanen, C. E. Mitchell, A. G. Power, W. Godsoe, and J. N. Klironomos. 2005. Enemy release? An experiment with congeneric plant pairs and diverse above- and belowground enemies. Ecology 86:2979-2989.

Andow, D. A. 1991. Vegetational diversity and arthropod population response. Annual Review of Entomology 36:561586.

Burghardt, K. T., D. W. Tallamy, C. Philips, and K. J. Shropshire. 2010. Nonnative plants reduce abundance, richness, and host specialization in Lepidoptera communities. Ecosphere 1:1-22.

Cardinale, B. J., K. L. Matulich, D. U. Hooper, J. E. Byrnes, E. Duffy, L. Gamfeldt, P. Balvanera, M. I. O'Connor, and A. Gonzalez. 2011. The functional role of producer diversity in ecosystems. American Journal of Botany 98:572-592.

Cardinale, B. J., J. P. Wright, M. W. Cadotte, I. T. Carroll, A. Hector, D. S. Srivastava, M. Loreau, and J. J. Weis. 2007. Impacts of plant diversity on biomass production increase through time because of species complementarity. Proceedings of the National Academy of Sciences USA 104:1812318128.

Carroll, I. T., B. J. Cardinale, and R. M. Nisbet. 2011. Niche and fitness differences relate the maintenance of diversity to ecosystem function. Ecology 92:1157-1165.

Chesson, P. 2000. Mechanisms of maintenance of species diversity. Annual Review of Ecology and Systematics 31: 343-366.

Cook-Patton, S. C., S. H. McArt, A. L. Parachnowitsch, J. S. Thaler, and A. A. Agrawal. 2011. A direct comparison of the consequences of plant genotypic and species diversity on communities and ecosystem function. Ecology 92:915-923.

Cronon, W. 1983. Changes in the land: Indians, colonists, and the ecology of New England. Hill and Wang, New York, New York, USA.
Dukes, J. S. 2001. Productivity and complementarity in grassland microcosms of varying diversity. Oikos 94:468480.

Fridley, J. D. 2002. Resource availability dominates and alters the relationship between species diversity and ecosystem productivity in experimental plant communities. Oecologia 132:271-277.

Gotelli, N. J., and R. K. Colwell. 2001. Quantifying biodiversity: procedures and pitfalls in the measurement and comparison of species richness. Ecology Letters 4:379-391.

Haddad, N. M., D. Tilman, J. Haarstad, M. Ritchie, and J. M. H. Knops. 2001. Contrasting effects of plant richness and composition on insect communities: a field experiment. American Naturalist 158:17-35.

Hooper, D. U., et al. 2005. Effects of biodiversity on ecosystem functioning: A consensus of current knowledge. Ecological Monographs 75:3-35.

Hutchinson, G. E. 1959. Homage to Santa Rosalia or Why are there so many kinds of animals? American Naturalist 93:145159.

Isbell, F. I., and B. J. Wilsey. 2011. Increasing native, but not exotic biodiversity increases aboveground productivity in ungrazed and intensely grazed grasslands. Oecologia 165: $771-781$.

Jahner, J. P., M. M. Bonilla, K. J. Badik, A. M. Shapiro, and M. L. Forister. 2011. Use of exotic hosts by Lepidoptera: widespread species colonize more novel hosts. Evolution 65: 2719-2724.

Johnson, M. T. J., M. J. Lajeunesse, and A. A. Agrawal. 2006. Additive and interactive effects of plant genotypic diversity on arthropod communities and plant fitness. Ecology Letters 9:24-34.

Karban, R., C. Karban, M. Huntzinger, I. Pearse, and G. Crustinger. 2010. Diet mixing enhances the performance of a generalist caterpillar, Platyprepia virginalis. Ecological Entomology 35:92-99.

Keane, R. M., and M. J. Crawley. 2002. Exotic plant invasions and the enemy release hypothesis. Trends in Ecology and Evolution 17:164-170.

Lau, J. A., and S. Y. Strauss. 2005. Insect herbivores drive important indirect effects of exotic plants on native communities. Ecology 86:2990-2997.

Levine, J. M., M. Vilà, C. M. D'Antonio, J. S. Dukes, K. Grigulis, and S. Lavorel. 2003. Mechanisms underlying the impacts of exotic plant invasions. Proceedings of the Royal Society B 270:775-781.

Loreau, M., and A. Hector. 2001. Partitioning selection and complementarity in biodiversity experiments. Nature 412:7276.

Mack, R. N., and W. M. Lonsdale. 2001. Humans as global plant dispersers: Getting more than we bargained for. BioScience 51:95-102.

Mack, R. N., D. Simberloff, W. M. Lonsdale, H. Evans, M. Clout, and F. A. Bazzaz. 2000. Biotic invasions: causes, epidemiology, global consequences, and control. Ecological Applications 10:689-710.

Marks, P. L. 1983. On the origin of the field plants of the northeastern United States. American Naturalist 122:210 228.

Marks, P. L., F. R. Wesley, and S. Gardescu. 2008. The vascular plant diversity of the Finger Lakes region of central New York State: changes in the 1800s and 1900s. Journal of the Torrey Botanical Society 135:53-69.

Mascaro, J., R. F. Hughes, and S. A. Schnitzer. 2012. Novel forests maintain ecosystem processes after the decline of native tree species. Ecological Monographs 82:221-228.

Murdoch, W. W., F. C. Evans, and C. H. Peterson. 1972. Diversity and pattern in plants and insects. Ecology 53:819829.

Oksanen, J., et al. 2011. Community ecology package vegan. http://vegan.r-forge.r-project.org 
R Development Core Team. 2012. R version 2.15.2. The $\mathrm{R}$ project for statistical computing. R Foundation for Statistical Computing, Vienna, Austria.

Reich, P., et al. 2001. Plant diversity enhances ecosystem responses to elevated $\mathrm{CO}_{2}$ and nitrogen deposition. Nature 410:809-812.

Root, R. B. 1973. Organization of a plant-arthropod association in simple and diverse habitats: the fauna of collards (Brassica oleracea). Ecological Monographs 43:95-120.

Sala, O. E., et al. 2000. Global biodiversity scenarios for the year 2100. Science 287:1770-1774.

Sax, D. F., S. D. Gaines, and J. H. Brown. 2002. Species invasions exceed extinctions on islands worldwide: a comparative study of plants and birds. American Naturalist 160: 766-783.

Schnitzer, S. A., et al. 2011. Soil microbes drive the classic plant diversity-productivity patterns. Ecology 92:296-303.

Siemann, E., D. Tilman, J. Haarstad, and M. Ritchie. 1998. Experimental tests of the dependence of arthropod diversity on plant diversity. American Naturalist 152:738-750.

Srivastava, D. S., and J. H. Lawton. 1998. Why more productive sites have more species: an experimental test of the theory using tree-hole communities. American Naturalist 152:510-529.

Strong, D. R., J. H. Lawton, and R. Southwood. 1984. Insect on plants: community patterns and mechanisms. Harvard University Press, Cambridge, Massachusetts, USA.
Tahvanainen, J. O., and R. B. Root. 1972. The influence of vegetational diversity on the population ecology of a specialized herbivore, Phyllotreta cruciferae (Coleoptera: Chrysomelidae). Oecologia 10:321-346.

Tilman, D. 2011. Diversification, biotic interchange, and the universal trade-off hypothesis. American Naturalist 178:355368.

Traveset, A., and D. M. Richardson. 2006. Biological invasions as disruptors of plant reproductive mutualisms. Trends in Ecology and Evolution 21:208-216.

Turnbull, L. A., J. M. Levine, M. Loreau, and A. Hector. 2013. Coexistence, niches and biodiversity effects on ecosystem functioning. Ecology Letters 16:116-127.

Wilsey, B. J., P. P. Daneshgar, and H. W. Polley. 2011. Biodiversity, phenology and temporal niche differences between native- and novel exotic-dominated grasslands. Perspectives in Plant Ecology, Evolution and Systematics 13:265-276.

Wilsey, B. J., T. B. Teaschner, P. P. Daneshgar, F. I. Isbell, and H. W. Polley. 2009. Biodiversity maintenance mechanisms differ between native and novel exotic-dominated communities. Ecology Letters 12:432-442.

Yurkonis, K. A., S. J. Meiners, and B. E. Wachholder. 2005. Invasion impacts diversity through altered community dynamics. Journal of Ecology 93:1053-1061.

\section{Supplemental Material}

\section{Appendix A}

Species employed in the experiment (Ecological Archives E095-143-A1).

\section{Appendix B}

Trait measurements on natives and exotics (Ecological Archives E095-143-A2).

Appendix C

Partitioning of plant biomass into complementarity and selection (Ecological Archives E095-143-A3).

\section{Appendix D}

Synchronicity of phenological traits (Ecological Archives E095-143-A4). 


\section{Ecological Archives E095-143-A1}

\section{Susan C. Cook-Patton and Anurag A. Agrawal. 2014. Exotic plants contribute positively to biodiversity functions but reduce native seed production and arthropod richness. Ecology 95:1642-1650. http://dx.doi.org/10.1890/13-0782.1}

APPENDix A. Species employed in the experiment.

TABLE $\mathrm{A} 1$. The table includes species origin $(\mathrm{E}=$ exotic, $\mathrm{N}=$ native $)$ and annuality $(\mathrm{A}=$ annual, $\mathrm{B}=$ biennial, $\mathrm{P}=$ perennial) information, which derives from the United States Department of Agriculture's Plants Database (plants.usda.gov). In 2009, we replaced individuals that died (replant \%). These include annuals and biennials that completed their lifecycle in the first year (i.e., Daucus carota and Lobelia inflata), as well as all Verbascum thapsus which died very early in 2008. We assumed that $V$. thapsus did not tolerate the field conditions so in 2009 we replaced it with Leucanthemum vulgare. Finally, those species included in our analyses of seed production are marked with an X under the "seed?" column.

\begin{tabular}{|l|l|c|c|c|c|}
\hline \multicolumn{1}{|c|}{ Family } & \multicolumn{1}{|c|}{ Species } & origin & replant (\%) & annuality & seed? \\
\hline Apiaceae & Daucus carota & $\mathrm{E}$ & 87 & $\mathrm{~B}$ & \\
\hline Apocynaceae & Asclepias syriaca & $\mathrm{N}$ & 77 & $\mathrm{P}$ & \\
\hline Asteraceae & Centaurea stoebe & $\mathrm{E}$ & 0 & $\mathrm{BP}$ & $\mathrm{X}$ \\
\hline & Cichorium intybus & $\mathrm{E}$ & 0 & $\mathrm{BP}$ & $\mathrm{X}$ \\
\hline & Eupatorium perfoliatum & $\mathrm{N}$ & 0 & $\mathrm{P}$ & $\mathrm{X}$ \\
\hline & Eupatoriadelphus maculatus & $\mathrm{N}$ & 0 & $\mathrm{P}$ & $\mathrm{X}$ \\
\hline & Leucanthemum vulgare & $\mathrm{E}$ & 100 & $\mathrm{P}$ & \\
\hline & Rudbeckia hirta & $\mathrm{N}$ & 3 & $\mathrm{ABP}$ & $\mathrm{X}$ \\
\hline & Solidago altissima & $\mathrm{N}$ & 0 & $\mathrm{P}$ & $\mathrm{X}$ \\
\hline & Solidago juncea & $\mathrm{N}$ & 0 & $\mathrm{P}$ & $\mathrm{X}$ \\
\hline
\end{tabular}




\begin{tabular}{|c|c|c|c|c|c|}
\hline & Symphyotrichum lanceolatum & $\mathrm{N}$ & 0 & $\mathrm{P}$ & $\mathrm{X}$ \\
\hline & Symphyotrichum novae-angliae & $\mathrm{N}$ & 3 & $\mathrm{P}$ & $\mathrm{X}$ \\
\hline \multirow[t]{2}{*}{ Campanulaceae } & Campanula rapunculoides & E & 3 & $\mathrm{P}$ & $\mathrm{X}$ \\
\hline & Lobelia inflata & $\mathrm{N}$ & 100 & $\mathrm{P}$ & $\mathrm{X}$ \\
\hline \multirow[t]{3}{*}{ Caryophyllaceae } & Dianthus armeria & E & 3 & $\mathrm{AB}$ & $\mathrm{X}$ \\
\hline & Saponaria officinalis & E & 3 & $\mathrm{P}$ & $\mathrm{X}$ \\
\hline & Silene vulgaris & $\mathrm{E}$ & 3 & $\mathrm{P}$ & $\mathrm{X}$ \\
\hline \multirow[t]{2}{*}{ Clusiaceae } & Hypericum perforatum & $\mathrm{E}$ & 0 & $\mathrm{P}$ & $\mathrm{X}$ \\
\hline & Hypericum punctatum & $\mathrm{N}$ & 10 & $\mathrm{P}$ & $\mathrm{X}$ \\
\hline Dipsaceae & Dipsacus sativus \& D. laciniatus ${ }^{a}$ & $\mathrm{E}$ & 0 & B & $\mathrm{X}$ \\
\hline \multirow[t]{2}{*}{ Lamiaceae } & Clinopodium vulgare & $\mathrm{N}$ & 0 & $\mathrm{P}$ & $\mathrm{X}$ \\
\hline & Prunella vulgaris & $E^{b}$ & 8 & $\mathrm{P}$ & $\mathrm{X}$ \\
\hline \multirow[t]{2}{*}{ Onagraceae } & Epilobium coloratum & $\mathrm{N}$ & 5 & $\mathrm{P}$ & $\mathrm{X}$ \\
\hline & Epilobium parviflorum & $\mathrm{N}$ & 8 & $\mathrm{P}$ & $\mathrm{X}$ \\
\hline \multirow[t]{2}{*}{ Plantaginaceae } & Penstemon digitalis & $\mathrm{N}$ & 0 & $\mathrm{P}$ & $\mathrm{X}$ \\
\hline & Oenothera perennis & $\mathrm{N}$ & 3 & $P$ & $\mathrm{X}$ \\
\hline Poaceae & Elymus repens & E & 38 & $\mathrm{P}$ & \\
\hline
\end{tabular}




\begin{tabular}{|l|l|c|c|c|c|} 
& Elymus trachycaulus & $\mathrm{N}$ & 38 & $\mathrm{P}$ & $\mathrm{X}$ \\
\hline Polygonaceae & Rumex crispus & $\mathrm{E}$ & 8 & $\mathrm{~B}$ & $\mathrm{X}$ \\
\hline Scrophulariaceae & Linaria vulgaris & $\mathrm{E}$ & 0 & $\mathrm{P}$ & $\mathrm{X}$ \\
\hline & Verbascum blattaria & $\mathrm{E}$ & 58 & $\mathrm{~B}$ & $\mathrm{X}$ \\
\hline & Verbascum thapsus & $\mathrm{E}$ & $\mathrm{n} / \mathrm{a}$ & $\mathrm{B}$ & $\mathrm{n} / \mathrm{a}$ \\
\hline Verbenaceae & Verbena hastata & $\mathrm{N}$ & 0 & $\mathrm{BP}$ & $\mathrm{X}$ \\
\hline
\end{tabular}

a Dipsacus sativus seeds were contaminated with a few D. laciniatus seeds. As a result, individuals of $D$. laciniatus occurred three times in monoculture and once in polyculture.

b Prunella vulgaris is listed as a circumpolar species. We used the exotic varietal, Prunella vulgaris var. vulgaris. 


\section{Ecological Archives E095-143-A2}

\section{Susan C. Cook-Patton and Anurag A. Agrawal. 2014. Exotic plants contribute positively to biodiversity functions but reduce native seed production and arthropod richness. Ecology 95:1642-1650. http://dx.doi.org/10.1890/13-0782.1}

ApPENDIX B. Trait measurements on natives and exotics.

Using plants within monocultures, we measured ten traits that were related to overall plant morphology (height, branch number, internode length, biomass) and phenology (time to bolt, time to flower, flowering duration). We also quantified leaf-level traits related to herbivory (trichome density, leaf toughness, specific leaf area, leaf damage). Plant height (in units of $0.1 \mathrm{~cm}$ ) corresponded to the distance between the ground and the tip of the highest leaf when stretched. Branch number records the number of branches on each plant that initiated within the first $10 \mathrm{~cm}$ above the ground. We measured internode length (in units of $0.1 \mathrm{~cm}$ ) by taking the mean of three consecutive internodes. If the plant had less than three internodes we measured the mean of two internodes or a single internode. Biomass corresponded to dried weight of all aboveground biomass (0.1g). These data were collected in 2009.

We began the phenology survey on April 15th, 2009 and continued checking plants once a week until harvest. Time to bolt equaled the number of days between the survey start date and that date when each plant began to bolt. Time to flower was the number of days between survey start date and the day when the first fully-opened flower appears on each plant. Flower duration was the difference between the flowering start date and the flowering stop date. If a plant stopped flowering, but recommenced flowering during subsequent surveys, we used the final stop date.

To measure trichome density, we took a $29.29 \mathrm{~mm}^{2}$ hole punch from the tip of the youngest fully expanded leaf, centered on the mid-vein and used a dissecting scope to count trichomes on the top and bottom of each leaf disk. Specific leaf area (SLA, area/dry mass) is a measure of leaf density. To measure SLA( $\left.\mathrm{mm}^{2} / \mathrm{mg}\right)$, the leaf discs from the trichome count were dried at $45^{\circ} \mathrm{C}$ overnight and weighed to determine dry mass. We measured leaf toughness, which affects palatability of the leaves to herbivores with a penetrometer (Type 516, Chatillon Corp. NY) to record the amount of force required to penetrate the youngest fully expanded leaf on a plant. Trichome density, SLA and leaf toughness were measured in 2008. We calculated leaf damage as the mean the damage estimates recorded in June, early July and late July 2009.

We asked whether the exotic species were generally different than the native species in the traits measured. We first calculated a mean trait value per monoculture (to account for the non-independence of individuals within a monoculture) and used the means as data in our model ( $N=55-61$ depending on the trait). Note that the few Dipsacus laciniatus individuals were excluded from the calculations. Except for time to flower, flower duration and height, the trait data were $\ln +1$ transformed to improve the normality of the residuals. We ran univariate analyses of variance (ANOVA) with origin as the main effect.

For the traits measured, natives and exotics were not significantly different (Table B1). We found some evidence that exotics flowered earlier than natives $\left(F_{1,54}=4.6, p=0.0370\right)$. However, because we examined ten traits it may be that this single significant effect was due to chance (binomial expansion test, $p=0.329$ ).

TABLE B1. Mean trait values \pm standard deviation for natives and exotics in monoculture. Only time to flower significantly differed between native and exotic species pools. 


\begin{tabular}{|l|c|c|c|}
\hline \multicolumn{1}{|c|}{ Trait } & Exotic & Native & $\boldsymbol{p}$ value \\
\hline Time to bolt (days) & $37.3 \pm 28.4$ & $27.9 \pm 13.0$ & 0.1290 \\
\hline Time to flower (days) & $85.6 \pm 19.2$ & $100.1 \pm 30.4$ & $\mathbf{0 . 0 3 7 0}$ \\
\hline Flower duration (days) & $45.3 \pm 27.2$ & $37.9 \pm 13.9$ & 0.2070 \\
\hline Height (cm) & $70.3 \pm 49.9$ & $86.0 \pm 43.5$ & 0.1951 \\
\hline Number of branches & $7.2 \pm 8.5$ & $6.9 \pm 4.9$ & 0.2262 \\
\hline Iinternode length (cm) & $14.1 \pm 13.5$ & $14.8 \pm 12.1$ & 0.5412 \\
\hline Biomass (g) & $45.6 \pm 66.3$ & $48.2 \pm 40.1$ & 0.2905 \\
\hline Trichomes (hairs/cm) & $11.5 \pm 21.4$ & $14.4 \pm 14.3$ & 0.1100 \\
\hline Toughness & $105.4 \pm 33.5$ & $121.3 \pm 60.1$ & 0.5619 \\
\hline Damage (\% leaf tissue consumed) & $10.9 \pm 8.9$ & $15.9 \pm 13.0$ & 0.0565 \\
\hline SLA (mm $/$ mg) & $24.7 \pm 8.3$ & $24.8 \pm 9.1$ & 0.9943 \\
\hline
\end{tabular}




\section{Ecological Archives E095-143-A3}

\section{Susan C. Cook-Patton and Anurag A. Agrawal. 2014. Exotic plants contribute positively to biodiversity functions but reduce native seed production and arthropod richness. Ecology 95:1642-1650. http://dx.doi.org/10.1890/13-0782.1}

APPENDIX C. Partitioning of plant biomass into complementarity and selection.

We made a few modifications to the additive partitioning method of biomass into complementarity and selection effects (Loreau and Hector 2001) to account for contamination of Dipsacus sativus seeds with Dipsacus laciniatus. We used mean biomass of a single plant in monoculture for each species to calculate expected yields instead of the total biomass of an entire monoculture (Cook-Patton et al. 2011). This result produces mathematically equivalent results to the traditional method when the expected relative yield of a species in polyculture (i.e., RYEi) is set to one; in other words, it is expected to be identical to that of a single individual in monoculture. The additive partitioning method is outlined below with our modifications in bold. This method allowed us to use the mean biomass of Dipsacus sativus individuals in monoculture to predict D. sativus performance in polyculture and conversely the mean biomass of $D$. laciniatus individuals from monoculture to predict $D$. laciniatus performance in polyculture. We also replaced zero values with a marginal non-zero value $(0.001 \mathrm{~g})$ to facilitate calculations (Parker et al. 2010). Finally, we set the expected yield of $A$. syriaca in polycultures equal to the observed yield to remove the contribution of $A$. syriaca to the calculations.

Define for any polyculture:

$$
\begin{aligned}
& M_{i} \\
& Y_{O i} \\
& Y_{O}=\Sigma_{i} Y_{O i} \\
& R Y_{E i}=1 \\
& R Y_{O i}=Y_{O i} / M_{i} \\
& Y_{E i}=R Y_{E i} \cdot M i=M_{i} \\
& Y_{E}=\Sigma_{i} Y_{E i} \\
& \Delta R Y_{i}=R Y_{O i}-R Y_{E i} \\
& N
\end{aligned}
$$

\author{
average yield of an individual from species $i$ in monocul \\ observed yield of species $i$ in the polyculture \\ total observed yield of the polyculture \\ relative yield of species $i$ in polyculture is expected to be \\ identical to that in monoculture \\ observed relative yield of species $i$ in the polyculture \\ expected yield of an individual from species $i$ in the poly \\ total expected yield of the mixture \\ deviation from expected relative yield of species $i$ in the \\ polyculture \\ number of species in the polyculture
}

Complementarity is calculated as $N \Delta R Y_{i} M_{i}$, and selection is calculated as $N \cdot \operatorname{cov}\left(\Delta R Y_{i}, M i\right)$, The sum of these terms equals the overall difference between the actual yield in polycultures and the expected yield (i.e., $Y_{O}$ $\left.Y_{E}\right)$.

\section{LITERATURE CITED}

Cook-Patton, S. C., S. H. McArt, A. L. Parachnowitsch, J. S. Thaler, and A. A. Agrawal. 2011. A direct comparison of the consequences of plant genotypic and species diversity on communities and ecosystem 
function. Ecology 92:915-923.

Loreau, M., and A. Hector. 2001. Partitioning selection and complementarity in biodiversity experiments. Nature 412:72-76.

Parker, J. D., J. Salminen, and A. A. Agrawal. 2010. Herbivory enhances positive effects of plant genotypic diversity. Ecology Letters 13:553-563. 


\section{Ecological Archives E095-143-A4}

\section{Susan C. Cook-Patton and Anurag A. Agrawal. 2014. Exotic plants contribute positively to biodiversity functions but reduce native seed production and arthropod richness. Ecology 95:1642-1650. http://dx.doi.org/10.1890/13-0782.1}

APPENDIX D. Synchronicity of phenological traits.

Time to bolt equaled the number of days between the survey start date and that date when each plant began to bolt. Time to flower was the number of days between survey start date and the day when the first fully-opened flower appeared on each plant. The variance of each phenological trait was calculated among species within each plot, ln-transformed to improve the normality of the residuals and then analyzed with origin as the predictor variable. If variance is low within a plot, then that means all species bolted or flowered at similar times and were thus more synchronous, whereas if variance is high, then species were more asynchronous in these traits. Native and exotic polycultures had equally variable bolting times $\left(F_{1,57}=0.04, p=0.843\right)$. Native polycultures had more variable flowering times $\left(F_{1,57}=33.9, p<0.0001\right)$.

\begin{tabular}{|l|c|c|}
\hline \multicolumn{1}{|c|}{ Trait } & $\begin{array}{c}\text { Exotic-only } \\
\text { polycultures }\end{array}$ & $\begin{array}{c}\text { Native-only } \\
\text { polycultures }\end{array}$ \\
\hline Ttime to bolt & $181.7 \pm 183.9$ & $179.8 \pm 247.6$ \\
\hline Time to flower & $397.6 \pm 254.5$ & $916.5 \pm 387.3$ \\
\hline
\end{tabular}

